COLON

\title{
Testing for faecal calprotectin (PhiCal) in the Norwegian Colorectal Cancer Prevention trial on flexible sigmoidoscopy screening: comparison with an immunochemical test for occult blood (FlexSure OBT)
}

\author{
G Hoff, T Grotmol, E Thiis-Evensen, M Bretthaver, G Gondal, M H Vatn
}

Gut 2004;53:1329-1333. doi: 10.1136/gut.2004.039032

See end of article for authors' affiliations

Correspondence to: Dr G Hoff, The Cancer Registry of Norway, Montebello, N-0310 Oslo, Norway; hofg@online.no

Revised version received 19 February 2004 Accepted for publication 3 March 2004

\begin{abstract}
Background: Screening for colorectal cancer (CRC) using guaiac based faecal occult blood tests (FOBT) has an estimated programme sensitivity of $>60 \%$ but $<30 \%$ for strictly asymptomatic CRC in a single screening round. In search for improved non-invasive tests for screening, we compared a test for faecal calprotectin (PhiCal) with a human haemoglobin immunochemical FOBT (FlexSure OBT).

Methods: In the Norwegian Colorectal Cancer Prevention (NORCCAP) trial, screenees in one screening arm were offered screening with combined flexible sigmoidoscopy (FS) and FlexSure OBT. They were also requested to bring a fresh frozen sample of stool for the PhiCal test which was performed on samples from screenees with CRC $(n=16)$, high risk adenoma $(n=195)$, low risk adenoma $(n=592)$, and no adenoma $(n=1518)$ (2321 screenees in total). A positive PhiCal test was defined by a calprotectin level $\geqslant 50 \mu \mathrm{g} / \mathrm{g}$. Results: The PhiCal test was positive in $24-27 \%$ of screenees whether they had no adenoma, low risk adenoma, or high risk adenoma. Ten (63\%) of 16 CRCs gave a positive PhiCal test. The total positivity rate in this population was $25 \%$ for the PhiCal test compared with $12 \%$ for FlexSure OBT, with a sensitivity for advanced neoplasia of $27 \%$ and $35 \%$, respectively. Specificity for "any neoplasia" was $76 \%$ for the PhiCal test and $90 \%$ for FlexSure OBT.

Conclusions: In colorectal screening, the performance of the PhiCal test on a single spot from one stool sample was poorer than a single screening round with FlexSure OBT and cannot be recommended for population screening purposes. The findings indicate a place for FlexSure OBT in FOBT screening.
\end{abstract}

olorectal cancer (CRC) is one of the leading causes of cancer death in Western societies. Randomised screening studies using guaiac based faecal occult blood tests (FOBT) show a $15-33 \%$ reduction in CRC mortality. ${ }^{1-3}$ Although FOBT programme sensitivity for CRC has been estimated to be more than $60 \%,{ }^{4}$ the sensitivity for strictly asymptomatic CRC is less than $30 \%$ for a single screening round. ${ }^{5}$ Additionally, FOBT frequently fails to detect premalignant neoplasia, allowing very limited possibilities for intervention along the adenoma-carcinoma sequence of progression to cancer. Thus there is a need for improved non-invasive screening tools. Although screening programme sensitivity is of prime importance, test sensitivity (single round sensitivity) may give an approximate indication as to what time intervals may be allowed between screening rounds.

Calprotectin, a calcium binding protein in granulocytes, macrophages, and epithelial cells, has shown increased levels in stools from patients with bowel inflammation and CRC. Calprotectin is stable in refrigerated storage. ${ }^{6}$ It is also poorly degraded during passage through the gastrointestinal tract, and swallowed sputum during respiratory tract infections may possibly influence faecal calprotectin values. ${ }^{7}$ Although information on faecal calprotectin in asymptomatic CRC is limited, the sensitivity of a commercially available calprotectin kit (PhiCal; Eurospital Spa, Trieste, Italy) may be $>60 \%{ }^{8}$ but poorer specificity may require work up colonoscopy in $30 \%$ of screenees ${ }^{6}$ compared with $4-5 \%$ of screenees after screening with unrehydrated FOBT (Hemoccult-II). ${ }^{1}{ }^{10}$

FlexSure OBT (Beckman-Coulter Inc, Primary Care Diagnostics, Palo Alto, California, USA) is an immunochemical test for human haemoglobin which is presently not marketed. ${ }^{11}$ Another test, based on similar membrane technology and immunolabelled colloidal gold to detect haemoglobin, but with a different sampling procedure, is available on the market (Insure, Enterix Inc., Portland, Maine, USA). ${ }^{12}$

In the Norwegian Colorectal Cancer Prevention (NORCCAP) screening trial, we used once only flexible sigmoidoscopy (FS) alone or in combination with FOBT. A low threshold for a positive FS (bioptically verified adenoma at FS or a positive FOBT) created work up colonoscopy in $20 \%$ of screenees, ${ }^{13}{ }^{14}$ approaching the proportion expected when using the PhiCal test. We therefore wished to explore the performance of the PhiCal test in this large scale population screening study by analysis of fresh frozen specimens of stool delivered by screenees on attendance for FS.

\section{METHODS}

In the NORCCAP trial, 20780 men and women, aged 50-64 years and living in Telemark County or the City of Oslo, were obtained by randomisation from the National Central Person Registry to be offered a colorectal screening examination. The design of the trial has been presented in detail elsewhere. ${ }^{13}$ A letter of invitation suggesting a screening appointment on a given date was posted to those randomised for screening. Altogether, $777(4 \%)$ persons were excluded according to exclusion criteria. ${ }^{13}$ Thus 20003 individuals remained eligible for screening, of which 12960 attended $(65 \%)$.

Abbreviations: $O R$, odds ratio 
Those invited were randomised $(1: 1)$ to screening with either FS alone or a combination of FS and FOBT using three stool samples for an immunochemical test for human blood, FlexSure OBT. In addition, screenees in the combined FSFOBT arm were asked to bring a fresh frozen stool specimen for research purposes. In the letter of invitation, addition of FOBT to FS was advocated as an add on screening option, the value of which should be explored through the trial. Participants were not given an option of FOBT screening without FS. Screenees collected their single stool sample at home less than one week before FS and kept it in a $20 \mathrm{ml}$ vial in their home deep freeze $\left(-20^{\circ} \mathrm{C}\right)$ until attendance for FS.

"Any bioptically verified neoplasia" at FS or a positive FOBT qualified for colonoscopy. Thus screen negative individuals had an FS examination only and no colonoscopy. The outcome of faecal calprotectin analysis was not used as a criterion for work up colonoscopy.

In the present study of faecal calprotectin, only screenees in the FS-FOBT group were included (that is, individuals who had also been asked to bring a frozen stool sample). All participants with neoplasia at FS and/or colonoscopy who had brought a stool sample $(n=929)$ were selected for faecal calprotectin analysis in addition to a random sample of screenees with no neoplasia $(n=1518$, representing $29 \%$ of screenees with no neoplasia, compared with $75 \%$ of individuals with neoplasia) (table 1). Also, as "any adenoma at FS" or "a positive FOBT" was a threshold for colonoscopy, only $4.8 \%$ of individuals with "no adenoma" in table 1 had colonoscopy after FS compared with $94 \%, 98 \%$, and 100\% in the low risk, high risk, and CRC groups, respectively. Thus this substudy on calprotectin did not reflect the prevalence of neoplasia in the overall screened population. Analysis of absolute test performance was therefore limited to test sensitivity and specificity as the predictive values of a test are influenced by the prevalence of the condition to be tested for. A total of 126 (14\%) of the 929 stool samples from screenees with neoplasia could not be analysed due to sample destruction (thawing) or inadequate labelling of stool vials for identification.

A subgroup of FS positive screenees subjected to colonoscopy was analysed separately to further compare the sensitivity of one round of the FlexSure OBT (three stool samples) and the PhiCal test (single stool sample). This group consisted of screen positive individuals who had delivered a valid FOBT (all three test windows used) and a faecal calprotectin analysis had been performed and colonoscopy work up had been accepted and performed with successful caecal intubation.

Nurses and nurse assistants at each screening centre were trained and certified for FlexSure OBT analysis by the manufacturer before being allowed to develop and read the test. ${ }^{15}$ They were re-certified after six months. For faecal calprotectin analysis, we used the PhiCal test. ${ }^{6}$ Fully trained laboratory technicians at the Research Institute of Internal Medicine (IIF), Rikshospitalet, Norway, and specially trained staff in NORCCAP performed all of the calprotectin analyses. Calprotectin values were recorded in $\mu \mathrm{g} / \mathrm{g}$ of stool. A positive PhiCal test was defined as faecal calprotectin $\geqslant 50 \mu \mathrm{g} / \mathrm{g}$ in a single stool specimen, as recommended by the manufacturer. ${ }^{8}$ Median time from attendance to calprotectin analysis of stored stool sample was 13 months (range 0-35). Being a remarkably stable protein, this should not pose a problem. ${ }^{6}{ }^{16}$ The oldest age groups were screened during the first two years of the trial, predisposing for longer sample storage before a PhiCal test was performed at leisure. FOBT was performed on attendance. A total of 6266 (63\%) out of 9990 eligible for screening attended the FS-FOBT arm of the study.

\section{Statistics}

Individuals were categorised according to the single most significant lesion found at screening or baseline work up of screen positives (that is, cancer; high risk adenoma (adenoma $\geqslant 10 \mathrm{~mm}$ diameter and/or adenoma with severe dysplasia and/or adenoma with villous components); low risk adenoma (adenoma not fulfilling the criteria for high risk adenoma or carcinoma); or no neoplasia (no adenoma or carcinoma). The $\chi^{2}$ test was used for comparative analysis of categorical data, and non-parametric analysis of variance (Kruskal-Wallis test) for quantitative data. A non-parametric test was chosen due to highly right skewed data distributions. When the overall analyses resulted in significance $(\mathrm{p}<0.05)$, the subgroup or category which tended to differ was identified by pairwise comparisons employing the $\chi^{2}$ test and Mann-Whitney test for categorical data and quantitative data, respectively. To avoid spurious statistical significance due to multiple comparisons, the level of significance was reduced to 0.01 for each of the three comparisons being performed in those cases (table 1).

A logistic regression model was applied using a positive or negative PhiCal test as the dependent binary variable. Age of screenee, month of the year for stool sampling, and duration of stool sample storage before calprotectin analysis (in months) were included as continuous covariates, with sex and neoplasia category as categorical variates. The SPSS statistical software, version 11.0, was used (SPSS Inc, Chicago, Illinois, USA).

\section{Ethics}

The regional ethics committee and the National Institute of Data Inspection approved the study protocol. Written informed consent was obtained from all participants before entering the trial.

Table 1 Relationship between the selected fraction $(n=2321)$ analysed for faecal calprotectin and the total flexible sigmoidoscopy-faecal occult blood test (FS-FOBT) group (\%)

\begin{tabular}{|c|c|c|c|c|c|}
\hline $\begin{array}{l}\text { Most significant lesion, } \\
\text { if any, at FS and/or } \\
\text { colonoscopy }\end{array}$ & $\begin{array}{l}\text { No of screenees } \\
\text { examined } \\
\text { with FS-FOBT }\end{array}$ & $\begin{array}{l}\text { No of screenees } \\
\text { delivering a frozen } \\
\text { stool specimen }\end{array}$ & $\begin{array}{l}\text { No of screenees } \\
\text { examined with } \\
\text { calprotectin analysis }\end{array}$ & $\begin{array}{l}\text { Calprotectin }(\mu \mathrm{g} / \mathrm{g}) \\
\text { (median [mean] (range)) }\end{array}$ & $\begin{array}{l}\text { Positive } \\
\text { PhiCal test }\end{array}$ \\
\hline No adenoma & 5192 & $4413(85)$ & $1518(29)$ & $\begin{array}{l}21.5[55.2] \\
(15.6-2092.2)\end{array}$ & $363(24)$ \\
\hline Low risk adenoma & 796 & $681(86)$ & $592(74)$ & $\begin{array}{l}21.0[46.7] \\
(15.6-772.0)\end{array}$ & $152(26)$ \\
\hline High risk adenoma & 258 & $231(90)$ & $195(76)$ & $\begin{array}{l}24.0[51.7] \\
(15.6-616.8)\end{array}$ & $52(27)$ \\
\hline CRC & 20 & $17(85)$ & $16(80)$ & $\begin{array}{l}66.1[156.5] \\
(15.6-1245.0)^{\star *}\end{array}$ & $10(63)^{* *}$ \\
\hline Total & 6266 & $5342(85)$ & 2321 (37) & & \\
\hline
\end{tabular}

CRC, colorectal cancer.

${ }^{* *} \mathrm{p}<0.01$ compared with the three other categories, assessed by the Mann-Whitney test and the $\chi^{2}$ test for quantitative and categorical data, respectively. Overall significance $(p<0.05)$ was initially achieved by the Kruskal-Wallis test and the $\chi^{2}$ test for the two types of data, respectively. 
Table 2 Crude and adjusted odds ratios (OR with 95\% confidence interval (CI)) of having a positive PhiCal test, adjusting for sex, age, duration of sample storage before analysis, and month of sample collection

\begin{tabular}{|c|c|c|c|c|c|c|}
\hline & $\begin{array}{l}\text { No of } \\
\text { screenees }\end{array}$ & $\begin{array}{l}\text { Crude } \\
\text { OR }\end{array}$ & $95 \% \mathrm{Cl}$ & $\begin{array}{l}\text { Adjusted } \\
\text { OR }\end{array}$ & $\begin{array}{l}\text { Adjusted } \\
95 \% \mathrm{CI}\end{array}$ & p Value \\
\hline \multicolumn{7}{|l|}{ Neoplasia status } \\
\hline No adenoma & 1518 & 1.0 & Reference & 1.0 & Reference & \\
\hline Any neoplasia & 803 & 1.16 & $0.95-1.41$ & 1.18 & $0.96-1.44$ & 0.11 \\
\hline Low risk adenoma & 592 & 1.10 & $0.88-1.37$ & 1.13 & $0.90-1.41$ & 0.30 \\
\hline High risk adenoma & 195 & 1.16 & $0.83-1.62$ & 1.16 & $0.82-1.63$ & 0.40 \\
\hline Colorectal cancer & 16 & 5.30 & $1.91-14.09$ & 5.40 & $1.94-15.02$ & $<0.01$ \\
\hline Sext & 2321 & 1.01 & $0.83-1.22$ & 1.01 & $0.83-1.22$ & 0.94 \\
\hline Age $(y)$ & 2321 & 1.03 & $1.01-1.06$ & 1.03 & $1.00-1.06$ & 0.04 \\
\hline Sample storagef & 2321 & 1.03 & $1.01-1.05$ & 1.02 & $1.00-1.05$ & 0.03 \\
\hline Stool sampled§ & 2321 & 0.35 & $0.97-1.02$ & 1.00 & $0.97-1.03$ & 0.84 \\
\hline
\end{tabular}

†Women as reference category.

$\ddagger$ Number of months of storage at $-20^{\circ} \mathrm{C}$ of fresh frozen stool sample.

$\S$ Month of the year when stool was sampled.

\section{RESULTS}

In the FS-FOBT group, 6266 (63\%) of 9990 attended for FS, 5098 (51\%) with a valid FOBT test, and 5342 (53\%) individuals brought a fresh frozen stool sample for calprotectin analysis.

Faecal calprotectin was analysed in 2321 individuals $(49 \%$ men) with a mean age of 58 years (range 50-64). There was no difference in faecal calprotectin concentrations in the three groups with no adenoma, low risk adenoma, and high risk adenoma, respectively $(p=0.19)$, whereas the group with CRC showed significantly higher calprotectin values than each of the other groups (table 1). Similarly, there was no difference between these first three groups in the frequency of a positive PhiCal test $(p=0,55)$. Again, the CRC group had a higher positivity rate than any of the other groups (table 1). Thus only individuals with cancer (all asymptomatic) demonstrated a significantly increased odds ratio $(\mathrm{OR})$ of having a positive PhiCal test $(\mathrm{p}<0.01)$ (table 2 ).

There was no difference in calprotectin levels or in the OR for having a positive PhiCal test in any one month of the year in which stool was sampled.

For those delivering valid samples for FlexSure OBT and having a PhiCal test, the overall positivity rate was $12 \%$ and
$25 \%$, respectively $(\mathrm{p}<0.01)$ (table 3$)$. The OR for "any neoplasia" giving a positive FlexSure OBT was 1.72 (95\% confidence interval (CI) 1.32-2.24) $(\mathrm{p}<0.01)$ compared with 1.11 (95\% CI 0.91-1.36) for the PhiCal test. The PhiCal test was also poorer in differentiating between advanced lesions (high risk adenoma or CRC) on the one hand and no neoplasia or low risk lesions on the other (table 3). The OR for advanced lesions giving a positive test compared with low risk or no adenoma detected at FS was 1.25 (95\% CI $0.91-$ $1,72)$ for PhiCal and 5.16 (95\% CI 3.72-7.14) $(\mathrm{p}<0.01)$ for FlexSure OBT. Although there was a considerable difference between the high and low risk adenoma groups in size distribution $(76 \% \geqslant 10 \mathrm{~mm} v$ none, respectively), the PhiCal positivity rate was $26 \%$ in both groups and similar to the group with no neoplasia (24\%) (table 3 ). Thus the sensitivity for "any neoplasia" was 27\% (204 of 766) with a specificity of $76 \%$ (1090 of 1427) for the PhiCal test. Corresponding values were 16\% (121 of 766) and 90\% (1289 of 1427) for FlexSure OBT (table 3).

In total, 666 individuals with neoplasia had a valid FOBT, faecal calprotectin analysis, and successful caecal intubation at colonoscopy. The difference in test performance observed in the total material was verified in this subgroup subjected

Table 3 Comparison of FlexSure OBT and the PhiCal test in 2193 participants with valid tests (\%)*

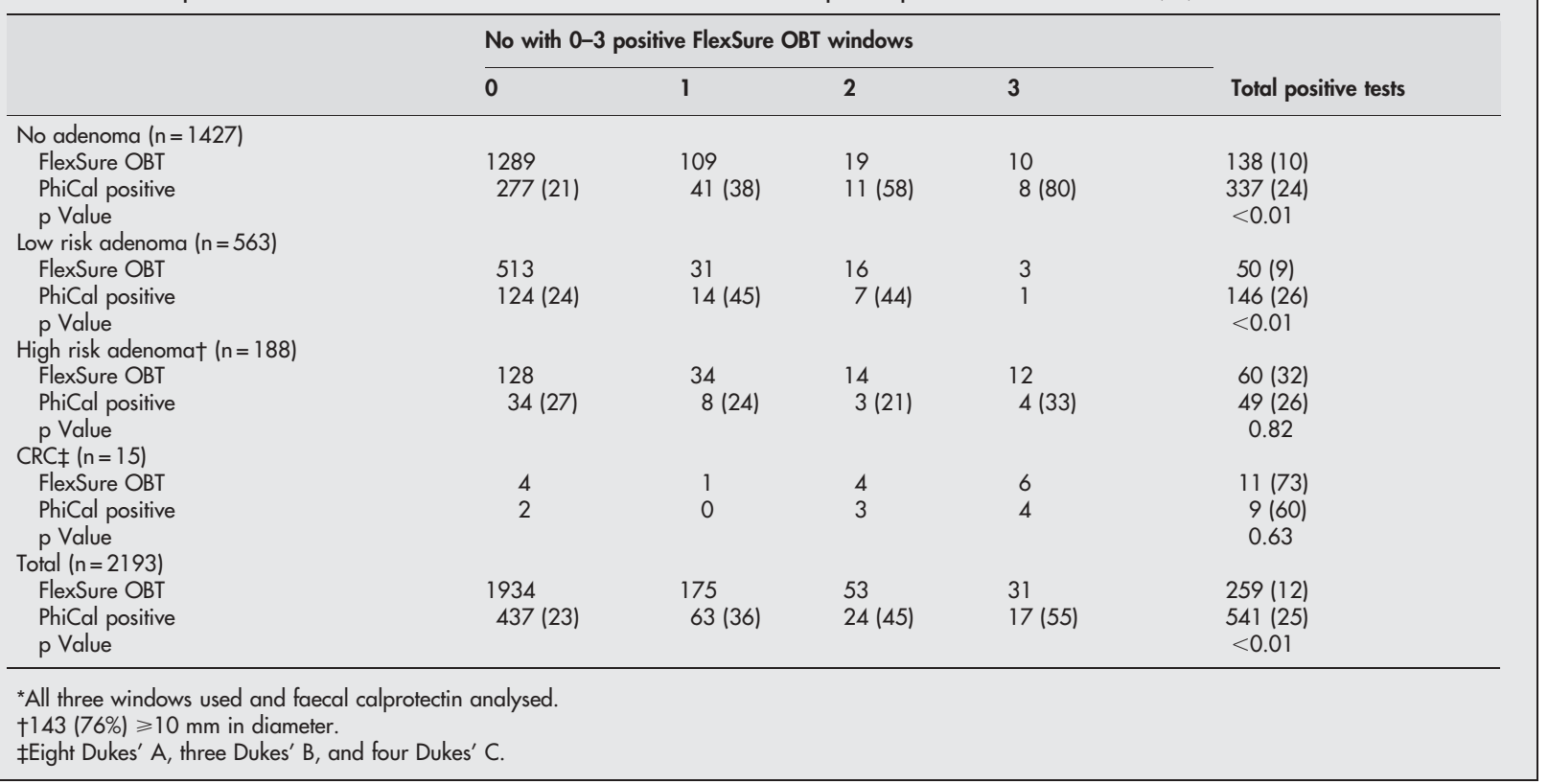




\begin{tabular}{|c|c|c|c|}
\hline & $\begin{array}{l}\text { Low risk adenoma } \\
(\mathrm{n}=480)\end{array}$ & $\begin{array}{l}\text { High risk adenoma } \\
(\mathrm{n}=174)\end{array}$ & $\begin{array}{l}\text { CRC } \\
(n=12)\end{array}$ \\
\hline Positive PhiCal & $125(26)$ & $43(25)$ & $8(67)$ \\
\hline Positive FlexSure OBT & $48(10)$ & $56(32)$ & $9(75)$ \\
\hline Any one test positive & $131(27)$ & 73 (42) & 5 \\
\hline Both tests positive & 21 (4.4) & $13(7.5)$ & 6 \\
\hline
\end{tabular}

to full colonoscopy. Again, the ORs for advanced lesions giving a positive test compared with low risk adenomas was 1.07 (95\% CI 0.73-1.57) for PhiCal and 4.86 (95\% CI 3.847.34) for FlexSure OBT $(\mathrm{p}<0.01)$. Sensitivity for advanced neoplasia (CRC or high risk adenoma) was $27 \%$ (51 of 186) and 35\% (65 of 186), respectively, for PhiCal and FlexSure OBT (table 4). Collectively, both tests failed to identify 88 (51\%) patients with high risk adenoma but only one of 12 CRCs.

\section{DISCUSSION}

The overall positivity rate was $25 \%$ for the PhiCal test and $12 \%$ for FlexSure OBT, with poorer sensitivity for advanced neoplasia and poorer specificity when using the former test alone.

The present study on calprotectin in stool samples from 2321 individuals is, as far as we are aware, the largest ever and the only one with recruitment from a large scale screening study of a population of average risk for CRC. A sensitivity of $67 \%$ for CRC is very much in accordance with that observed by Johne et al $(64 \%)^{8}$ when using one sample from one stool and the recommended $50 \mu \mathrm{g} / \mathrm{g}$ as the cut off for the PhiCal test. Similar to our study, Kronborg and colleagues $^{7}$ found no difference in calprotectin levels when comparing one spot samples from adenoma patients and patients with no polyps at colonoscopy. They did however find increased levels in stools from adenoma patients when performing two spots in each of 1-2 stools. But independent of the number of spots tested, they found no reduction in faecal calprotectin levels 6-12 weeks after polypectomy, suggesting that increased faecal calprotectin may be due to a general mucosal defect rather than the mere presence of adenomas. Differences in possible sources of marker protein were also reflected in our material, expressed by differences in test response to size of lesions. PhiCal tested positive in $26 \%$ of adenomas whether they were small, low risk (all $<10 \mathrm{~mm})$, or high-risk $(76 \% \geqslant 10 \mathrm{~mm})$ whereas faecal blood seemed to be more associated with surface area/size of the lesion (table 3). Our finding of $24-27 \%$ PhiCal positivity rate whether screenees had no adenoma, low risk adenoma, or high-risk adenoma does however emphasise the accumulating knowledge that there is probably no place for faecal calprotectin as a screening tool in average risk individuals.

Similar to the PhiCal test, FlexSure OBT does not require dietary restriction and it is probably one of the most sensitive and specific FOBTs available. ${ }^{11}{ }^{17}$ We have previously reported from the NORCCAP trial that addition of FOBT to FS screening may reduce attendance by $4 \%$. An intention to diagnose analysis revealed that even the sensitive FlexSure OBT test could not compensate for loss in diagnostic yield caused by the $4 \%$ drop in attendance rate. ${ }^{14}$ Adding presently available FOBTs to FS screening may therefore not be the solution to our shortcomings in developing the perfect single screening modality, particularly if high attendance rates for FS are anticipated. ${ }^{18}$ The sensitivity of FlexSure OBT for detecting advanced neoplasia was better than PhiCal in the present study. Also, the higher odds ratio of 4-5 for advanced lesions giving a positive FlexSure OBT indicates a place for FlexSure OBT in FOBT screening. The FlexSure OBT slides were developed on site on attendance whereas calprotectin was analysed after 0-35 months of storage of the stool samples at $-20^{\circ} \mathrm{C}$. The observed $3 \%$ increase in PhiCal positivity rate for each month of sample storage may be explained by the longer storage for samples from older screenees. However, both age and length of storage were adjusted for in the logistic regression model. We also adjusted for month of the year of sampling as respiratory tract infections are believed to influence faecal calprotectin levels and these infections are very abundant during the winter months in Norway. Univariate analysis did not however reveal any difference in calprotectin levels (data not shown) or in the OR for having a positive PhiCal test in any one month of the year of stool sampling.

One obvious disadvantage with this study is that individuals with a negative FS and/or a negative FOBT were not subjected to full colonoscopy, thus overestimating particularly the sensitivity, but also the specificity, of the tests used. A colonoscopy study using the first part of the examination as a surrogate FS showed that $2.7 \%$ of FS negative screenees had proximal advanced neoplasia. ${ }^{19}$ This suggests that there may be 140 cases of undiagnosed advanced neoplasia among our 5192 adenoma free screenees, and furthermore that we may have only diagnosed $(258+20) /(258+20+140)=67 \%$ of cases with advanced neoplasia in our material. This however should not interfere with the comparative test performance between the FlexSure OBT and PhiCal tests and the absolute sensitivity findings among those subjected to full colonoscopy. The possibility of recording positive tests from upper gastrointestinal lesions or respiratory tract infections (for the PhiCal test) was not accounted for in the present study.

\section{CONCLUSIONS}

In conclusion, the performance of a single spot from one stool sample using the PhiCal test in colorectal screening was poorer than a single screening round with FlexSure OBT and cannot be recommended for population screening purposes. If increased faecal calprotectin levels express a general mucosal defect and predisposition for neoplasia, ${ }^{7}$ then five year follow up results of screenees in the NORCCAP trial, due in 2006-7, may be of particular interest. The high sensitivity of FlexSure OBT, not negated by the poor specificity demonstrated for PhiCal, indicates a place for FlexSure OBT in FOBT screening.

\section{ACKNOWLEDGEMENTS}

We owe thanks to the Norwegian Cancer Society and the Ministry of Health and Social Affairs for financial support and to the Norwegian Gastrointestinal Cancer Group (NGICG) for initiating the study. The technical assistance of Kristin Høimyr, Jorunn Bratlie, Tove Hamborg, and Marianne Nilsen was greatly appreciated, as were the samples for certification and re-certification of nurses supplied by Beckman-Coulter Inc. 


\section{Authors' affiliations}

G Hoff, T Grotmol, M Bretthauer, G Gondal, The Cancer Registry of Norway, Montebello, N-0310 Oslo, Norway

E Thiis-Evensen, M H Vatn, The Research Institute of Internal Medicine

(IIF), Rikshospitalet University Hospital, N-0027 Oslo, Norway

\section{REFERENCES}

1 Hardcastle JD, Chamberlain JO, Robinson MHE, et al. Randomised controlled trial of faecal occult-blood screening for colorectal cancer. Lancet 1996:348:1472-7.

2 Kronborg O, Fenger C, Olsen J, et al. Randomised study of screening for colorectal cancer with faecal occult-blood test. Lancet 1996;348:1467-71.

3 Mandel JS, Bond JH, Church TR, et al. Reducing mortality from colorectal cancer by screening for fecal occult blood. N Engl J Med 1993;328:1365-71.

$4 \mathrm{Kronborg} \mathrm{O}$. Screening for colorectal cancer in the average-risk population. Semin Colon Rectal Surg 2002;13:16-30.

5 Ahlquist DA, Shuber AP. Stool screening for colorectal cancer: evolution from occult blood to molecular markers. Clin Chim Acta 2002;315:157-68.

6 Tøn $\mathrm{H}$, Brandsnes $\varnothing$, Holtlund J, et al. Improved assay for fecal calprotectin Clin Chim Acta 2000;292:41-54.

7 Kronborg O, Ugstad M, Fuglerud P, et al. Faecal calprotectin levels in a high risk population for colorectal neoplasia. Gut 2000;46:795-800.

8 Johne B, Kronborg O, Tøn HI, et al. A new fecal cal protectin test for colorectal neoplasia. Clinical results and comparison with previous method. Scand J Gastroenterol 2001;36:291-6.

9 Kristinsson J, Nygard K, Aadland E, et al. Screening of first degree relatives of patients operated for colorectal cancer: evaluation of fecal calprotectin vs. Hemoccult II. Digestion 2001;64:104-10.
10 Jørgensen $O D$, Kronborg $O$, Fenger $C$. A randomised study of screening for colorectal cancer using faecal occult blood testing: results after 13 years and seven biennial screening rounds. Gut 2002;50:29-32.

11 Rozen P, Knaani J, Samuel Z. Performance characteristics and comparison of two immunochemical and two Guaiac fecal occult blood screening tests for colorectal neoplasia. Dig Dis Sci 1997;42:2064-71.

12 Cole SR, Young GP, Esterman A, et al. A randomized trial of the impact of new faecal hemoglobin test technologies on population participation in screening for colorectal cancer. J Med Screen 2003;10:117-22.

13 Bretthaver M, Gondal G, Larsen IK, et al. Design, organisation and management of a controlled population screening study for detection of colorectal neoplasia. Attendance rates in the NORCCAP study (Norwegian Colorectal Cancer Prevention). Scand J Gastroenterol 2002:37:568-73.

14 Gondal G, Grotmol T, Hofstad B, et al. The Norwegian Colorectal Cancer Prevention (NORCCAP) screening study: Baseline findings and implementations for clinical work-up in age groups 50-64 years. Scand J Gastroenterol 2003;38:635-42.

15 Bradshaw P. Fitzgerald D, Stephens L, et al. FlexSure Test Device: Qualitative immunochemical test format, Clin Chem 1995;41:1360-3.

16 Johne B, Fagerhol MK, Lyberg $T$, et al. Functional and clinical aspects of the myelomonocyłe protein calprotectin. Mol Pathol 1997:50:113-23.

17 Allison JE. Faecal occult blood testing for colorectal cancer. Aliment Pharmacol Ther 1998;12:1-10.

18 Hoff G. CRC screening: Review of the evidence and suggestions on when and how to move on from randomized trials to screening programmes. Scand J Gastroenterol 2004;39:99-103.

19 Lieberman DA, Weiss DG, Bond JH, et al. Use of colonoscopy to screen asymptomatic adults for colorectal cancer. N Engl J Med 2000;343:162-8. 